\title{
ESTIMATES OF GENETIC PARAMETERS AND REPEATABILITY COEFFICIENTS IN S PEACH GENOTYPES GROWN IN A SUBTROPICAL ENVIRONMENT
}

\author{
José Osmar da Costa e Silva ${ }^{1}$, Claudio Horst Bruckner ${ }^{1}$, Pedro Crescêncio Souza Carneiro ${ }^{2}$,
} Marcos Deon Vilela de Resende ${ }^{3}$, Rodrigo Silva Alves ${ }^{2}$, Rosana Gonçalves Pires Matias ${ }^{4}$

\begin{abstract}
1) Universidade Federal de Viçosa, Departamento de Fitotecnia, Campus Universitário, 36570-900, Viçosa, MG, Brasil; 2) Universidade Federal de Viçosa, Departamento de Biologia Geral, Campus Universitário, 36570-900, Viçosa, MG, Brasil; 3) Embrapa Café / Universidade Federal de Viçosa, Departamento de Estatística, Campus Universitário, 36570-900, Viçosa, $M G$, Brasil;

4) Universidade Federal de Viçosa, Departamento de Biologia Vegetal, Campus Universitário, 36570-900, Viçosa, MG, Brasil.
\end{abstract}

Corresponding author: José Osmarda Costa e Silva (joksilva7@yahoo.com.br)

\begin{abstract}
Estimates of genetic parameters and repeatability coefficients in peach breeding are scarce. In view of this, the present study was carried out to estimate genetic parameters for plant and fruit traits and repeatability coefficients for fruit traits in $S_{2}$ peach genotypes grown in a subtropical environment. A total of 434 individuals from 55 full-sib families of five populations were used in the study. The following plant traits were evaluated: trunk diameter at $10 \mathrm{~cm}$ above soil level (TD10), trunk diameter at $130 \mathrm{~cm}$ above soil level (TD130), plant height (PH), rate of budding on mixed branches (RB), rate of blind nodes on mixed branches (RBN), fruit number (FN) and harvest time (HT). In the fruit, the following traits were measured: weight (FW), diameter (FD), length (FL), diameter/length ratio (FD/FL), percentage of red in the epidermis (PRE), apex prominence (AP), suture line prominence (SLP), total soluble solids content (TSS), total titratable acidity (TTA) and TSS/TTA ratio (TSS/TTA). Repeated measures were performed for FD, FL, FD/FL, PRE, AP and SLP. Statistical analyses were run through the mixed model methodology. Genetic variability was detected for all traits. Individual narrowsense heritability values of moderate to high magnitude were found for the plant traits and of low to moderate magnitude for the fruit traits. Repeatability coefficients of moderate to high magnitude were obtained for the fruit traits. Except for the SLP trait, the evaluation of six fruits per plant revealed coefficients of determination higher than $80 \%$, indicating high accuracy.
\end{abstract}

Keywords: Prunus persica, fruit breeding, repeated measures, mixed models, genetic selection. 


\section{Introduction}

The cultivation of peach in regions with mild climatic conditions (subtropical or high-altitude tropical) carries some advantages in comparison to temperate regions. According to Topp and Sherman (2000), one of such advantages is earlier production compared to colder areas, which is due to early flowering and a shorter fruit development time. Another benefit is the possibility of meeting the demand for peach of those regions, thereby reducing transport costs.

The viability of peach growing in regions with mild winters is a result of the use of cultivars with low chill requirements (Thurow et al., 2017). Therefore, the breeding of peach for those regions is aimed mainly at the development of cultivars with a chill requirement compatible with the climate of those locations (Corrêa et al., 2019; Thurow et al., 2020).

In the peach crop, the most commonly employed breeding method is hybridization, followed by the technique of segregating populations, from which superior genotypes for given traits are selected. To develop genotypes adapted to regions with mild winters, at least one of the parents must have a low chill requirement (Raseira and Nakasu, 2002). Cultivars, selections, wild genotypes from regions with mild climatic conditions or genotypes of close species may be used as parents to obtain segregating populations (Topp and Sherman, 2000).

Peach is an autogamous perennial plant. Old peach cultivars, propagated by seeds, are lines. By contrast, modern cultivars, propagated vegetatively, are usually hybrids. To produce lines, six to seven cycles of self-pollination are required, and because each cycle lasts four to six years, the entire process takes approximately 40 years (Monet et al., 1996). In the case of vegetative propagation, individuals from the first generation are usually selected and released as cultivars. Only crosses aimed at improved quantitative traits or at the manifestation of recessive traits make it through the $\mathrm{S}_{1}$ generation (Raseira and Nakasu, 2002).

Although the development of lines may be prevented due to the required time, some self- pollination cycles may be necessary to improve traits controlled by genes of additive action and to obtain potential parents, making it possible to eliminate part of the undesirable alleles (Monet et al., 1996).

In this respect, reliable estimates of genetic parameters and repeatability coefficients of target traits for selection are crucial to the efficient development of fruit breeding programs (Viana and Resende, 2014). However, such information is scarce in peach breeding (Albuquerque et al., 2004; Bruna et al., 2012; Matias et al., 2015). On these bases, the present study was conducted to estimate genetic parameters for plant and fruit traits and repeatability coefficients for fruit traits in $S_{2}$ peach genotypes grown in a subtropical environment.

\section{Materials and methods}

\section{Genetic material, experimental design and traits assessed}

Seedlings were produced from $\mathrm{S}_{1}$ peach populations selected for budding rate. The experiment was implemented in June 2010 in Viçosa - MG, Brazil (20 $45^{\prime} 45^{\prime \prime}$ S latitude, 4249'27" W longitude; $647 \mathrm{~m}$ altitude), as a completely randomized design with rows spaced $3.0 \mathrm{~m}$ apart and plants $1.2 \mathrm{~m}$ apart. At two years of age, 434 individuals from 55 full-sib families of five populations were evaluated. All plant management operations were undertaken in accordance with the requirements of the crop in the region, and no fruit thinning was performed.

The following traits were evaluated in the plant: trunk diameter at $10 \mathrm{~cm}$ above soil level (TD10), trunk diameter at $130 \mathrm{~cm}$ above soil level (TD130), plant height $(\mathrm{PH})$, rate of budding on mixed branches $(\mathrm{RB})$, rate of blind nodes on mixed branches $(\mathrm{RBN})$, fruit number $(\mathrm{FN})$ and harvest time (HT).

The TD10, TD130 and PH were measured using a diameter tape. RB and RBN were evaluated in three branches, one in each third of the plant (upper, middle and lower). RB was calculated as number of shoots/total number of vegetative buds $(\%)$, and RBN was determined as the ratio between the number of nodes that did not develop buds 
(vegetative or flower) and the total number of nodes on the branch (\%). FN was measured prior to the harvest period. HT was determined as the number of days from the harvest of the earliest genotype to the harvest date of each genotype.

The following traits were evaluated in the fruit: weight (FW), diameter (FD), length (FL), diameter/length ratio (FD/FL), percentage of red in the epidermis (PRE), apex prominence (AP), suture line prominence (SLP), total soluble solids content (TSS), total titratable acidity (TTA) and TTS/TTA ratio (TSS/TTA). To evaluate these traits, a sample of three to six fruits was collected from each plant. Because some plants did not bear fruit, of the 434 individuals examined for plant traits, 316 were evaluated for fruit traits. The fruits were harvested at the point of maturation based on the change in epidermis background color (Cantillano and Sachs, 1984).

The FW was determined for each individual as the ratio between the total weight of harvested fruits and the total number of harvested fruits. FD was calculated as the average of the sutural (maximum distance in the middle region of the suture line to the opposite end) and equatorial lengths (median region perpendicular to the suture line). FL was determined as the average distance between the peduncle and the fruit apex (mm). PRE was measured visually, considering the shade of red pigmentation (\%). AP represents the size of the tip of the fruit, which was assessed on a 3-point scale $(1=$ small, $2=$ medium, and $3=$ large $)$. SLP represents the growth of the suture region on the fruit, which was also assessed using a 3-point scale $(1=$ small, $2=$ medium, and $3=$ large $)$. The TSS was measured in an aliquot of juice, using a digital refract meter (Brix). TTA was determined by titrating $5 \mathrm{~g}$ of homogenized pulp in $100 \mathrm{~mL}$ distilled water with $0.05 \mathrm{~N} \mathrm{NaOH}$, using phenolphthalein as an indicator (AOAC, 1990) ( $\mathrm{g}$ of malic acid/100 $\mathrm{g}$ of fresh weight).

The TSS, TTA and TSS/TTA traits were expressed as the average of three replicates, using a sample composed of all fruits harvested from each individual. The FD, FL, FD/FL, PRE, AP and SLP traits were measured individually.

\section{Statistical analyses}

The statistical model associated with the evaluation of genotypes of various populations, in a completely randomized design, with one observation per individual (TD10, TD130, PH, RB, RBN, FN, HT, FW, TSS, TTA and TSS/TTA), is given by the following equation:

$$
y=X u+Z a+W p+e, \quad(\text { Eq. 1) }
$$

where $y$ is the vector of data, $u$ is the scalar value referring to the overall mean effect (fixed), $a$ is the vector of individual additive genetic effects (assumed random), $p$ is the vector of population effects (assumed random) and $e$ is the vector of residuals (random). $X, Z$ and $W$ represent the incidence matrices for the $u, a$ and $p$, respectively.

The distributions and structures of means and variance for this model are given by:

$$
\begin{gathered}
y \mid u, V \sim N(X u, V), \\
a \mid A, \sigma_{a}^{2} \sim N\left(0, A \sigma_{a}^{2}\right), \\
p \mid \sigma_{p}^{2} \sim N\left(0, I \sigma_{p}^{2}\right), \\
e \mid \sigma_{e}^{2} \sim N\left(0, I \sigma_{e}^{2}\right), \text { and } \\
\operatorname{Cov}\left(a, p^{\prime}\right)=0 ; \operatorname{Cov}\left(a, e^{\prime}\right)=0 ; \operatorname{Cov}\left(p, e^{\prime}\right)=0,
\end{gathered}
$$

that is,

$$
E\left[\begin{array}{l}
y \\
a \\
p \\
e
\end{array}\right]=\left[\begin{array}{c}
X u \\
0 \\
0 \\
0
\end{array}\right] \text { and } \operatorname{Var}\left[\begin{array}{l}
y \\
a \\
p \\
e
\end{array}\right]=\left[\begin{array}{cccc}
V & Z G & W P & R \\
G Z^{\prime} & G & 0 & 0 \\
P W^{\prime} & 0 & P & 0 \\
R & 0 & 0 & R
\end{array}\right] \text {, }
$$

where

$$
\begin{gathered}
G=A \sigma_{a}^{2}, \\
P=I \sigma_{p}^{2}, \\
R=I \sigma_{e}^{2}, \text { and } \\
V=Z A \sigma_{a}^{2} Z^{\prime}+W I \sigma_{p}^{2} W^{\prime}+I \sigma_{e}^{2}=Z G Z^{\prime}+W P W^{\prime}+R \\
\text { (Eq. 2) }
\end{gathered}
$$

The mixed-model equations are given by:

$$
\left[\begin{array}{ccc}
X^{\prime} X & X^{\prime} Z & X^{\prime} W \\
Z^{\prime} X & Z^{\prime} Z+A^{-1} \lambda_{1} & Z^{\prime} W \\
W^{\prime} X & W^{\prime} Z & W^{\prime} W+I \lambda_{2}
\end{array}\right]\left[\begin{array}{c}
\hat{u} \\
\tilde{a} \\
\tilde{p}
\end{array}\right]=\left[\begin{array}{c}
X^{\prime} y \\
Z^{\prime} y \\
W^{\prime} y
\end{array}\right]
$$


where

$$
y=X u+Z a+W p+T i+Q r+e, \quad \text { (Eq. 10) }
$$

$$
\begin{aligned}
& \lambda_{1}=\frac{\sigma_{e}^{2}}{\sigma_{a}^{2}}=\frac{1-h^{2}-p^{2}}{h^{2}}, \quad \text { (Eq. 3) } \\
& \lambda_{2}=\frac{\sigma_{e}^{2}}{\sigma_{p}^{2}}=\frac{1-h^{2}-p^{2}}{p^{2}}, \quad \text { (Eq. 4) } \\
& h^{2}=\frac{\sigma_{a}^{2}}{\sigma_{a}^{2}+\sigma_{p}^{2}+\sigma_{e}^{2}}, \quad \text { (Eq. 5) and } \\
& p^{2}=\frac{\sigma_{p}^{2}}{\sigma_{a}^{2}+\sigma_{p}^{2}+\sigma_{e}^{2}} ; \quad \text { (Eq. 6) }
\end{aligned}
$$

where $h^{2}$ is the individual narrow-sense heritability, $p^{2}$ is the coefficient of determination of the genotypic effects of the population, $\sigma_{a}^{2}$ is the additive genetic variance, $\sigma_{p}^{2}$ is the genotypic variance between populations, $\sigma_{e}^{2}$ is the residual variance and $A$ is the matrix of additive genetic correlation between the evaluated individuals.

The iterative estimators of variance components by restricted maximum likelihood (REML), via the Expectation-Maximization (EM) algorithm, are given by:

$$
\begin{gathered}
\hat{\sigma}_{e}^{2}=\left[y^{\prime} y-\hat{u}^{\prime} X^{\prime} y-\hat{a}^{\prime} Z^{\prime} y-\hat{p}^{\prime} W^{\prime} y\right] /[N-r(X)], \\
\text { (Eq. 7) }
\end{gathered}
$$$$
\hat{\sigma}_{a}^{2}=\left[\hat{a}^{\prime} A^{-1} \hat{a}+\hat{\sigma}_{e}^{2} \operatorname{tr}\left(A^{-1} C^{22}\right)\right] / q \quad(\text { Eq. 8) and }
$$$$
\hat{\sigma}_{p}^{2}=\left[p^{\prime} p+\hat{\sigma}_{e}^{2} \operatorname{tr} C^{33}\right] / s ; \quad \text { (Eq. 9) }
$$

Where $C^{22}$ and $C^{33}$ derive from

$$
C^{-1}=\left[\begin{array}{lll}
C_{11} & C_{12} & C_{13} \\
C_{21} & C_{22} & C_{23} \\
C_{31} & C_{32} & C_{33}
\end{array}\right]^{-1}=\left[\begin{array}{lll}
C^{11} & C^{12} & C^{13} \\
C^{21} & C^{22} & C^{23} \\
C^{31} & C^{32} & C^{33}
\end{array}\right],
$$

where $C$ is the matrix of the coefficients of mixed-model equations, $t r$ is the trace matrix operator, $r(X)$ is the rank of matrix $X, N$ is the total number of data, $q$ is the number of individuals and $s$ is the number of plots.

The statistical model associated with the evaluation of genotypes from various populations, in a completely randomized design with repeated measures (FD, FL, FD/FL, PRE, AP and SLP), is given by the following equation: where $y$ is the vector of data, $u$ is the scalar value referring to the overall mean effect (fixed), $a$ is the vector of individual additive genetic effects (assumed random), $p$ is the vector of population effects (assumed random), $i$ is the vector of the genotype $\times$ measure interaction effects (random), $r$ is the vector of individual permanent effects (random) and $e$ is the vector of residuals (random). $X, Z, W, T$ and $Q$ represent the incidence matrices for the $u, a, p, i$ and $r$, respectively.

The estimators and predictors are obtained by expanding the above equations, which is achieved by including $i$ and $r$ effects.

The repeatability coefficient $(\rho)$ is given by the following equation:

$$
\rho=\frac{\sigma_{a}^{2}+\sigma_{p}^{2}+\sigma_{r}^{2}}{\sigma_{\text {phen }}^{2}}, \quad \text { (Eq. 11) }
$$

where $\sigma_{a}^{2}$ is the additive genetic variance, $\sigma_{p}^{2}$ is the genotypic variance between populations, $\sigma_{r}^{2}$ is the permanent environmental variance and $\sigma_{\text {phen }}^{2}$ is the phenotypic variance.

The coefficient of determination $\left(R^{2}\right)$ is given by the following equation:

$$
R^{2}=\frac{n \rho}{1+\rho(n-1)},
$$

where $n$ is the number of evaluated fruits.

The number of fruits $(\eta)$ required to obtain different precision levels $\left(R^{2}=0.80,0.90\right.$ and 0.95$)$ was estimated by the following equation:

$$
\eta=\frac{R^{2}(1-\rho)}{\left(1-R^{2}\right) \rho}
$$

The other genetic and non-genetic parameters were obtained following Resende (2007) and Resende et al. (2014). The analyses were carried out using Selegen-REML/BLUP software (Resende, 2016). 


\section{Results and discussion}

Estimates of variance components and genetic and non-genetic parameters for the plant traits are presented in Table 1. The genetic coefficients of variation indicated the existence of genetic variability for all traits. These coefficients were highest for FN (53.82\%), RBN (30.77\%) and HT $(24.48 \%)$. PH, on the other hand, showed the lowest coefficient of genetic variation $(8.93 \%)$.

Table 1. Estimates of variance components and genetic and non-genetic parameters for the following traits evaluated in $S_{2}$ peach genotypes at two years old: trunk diameter at $10 \mathrm{~cm}$ from soil level (TD10), trunk diameter at $130 \mathrm{~cm}$ from soil level (TD130), plant height (PH), rate of budding on mixed branches (RB), rate of blind nodes on mixed branches (RBN), fruit number $(\mathrm{FN})$ and harvest time $(\mathrm{HT})$.

\begin{tabular}{cccccccc}
\hline Estimate / Parameter & TD10 & TD130 & PH & RB & RBN & FN & HT \\
\hline $\boldsymbol{\sigma}_{\boldsymbol{a}}^{2}$ & 77.6669 & 96.4860 & 0.0822 & 58.6934 & 43.0530 & 306.2071 & 51.6538 \\
\hline $\boldsymbol{\sigma}_{\boldsymbol{p}}^{\mathbf{2}}$ & 9.5430 & 5.2393 & 0.0036 & 18.8987 & 2.7365 & 61.4644 & 19.1736 \\
\hline $\boldsymbol{\sigma}_{\boldsymbol{e}}^{\mathbf{2}}$ & 78.8897 & 65.2721 & 0.1103 & 112.1861 & 96.7256 & 923.5110 & 97.4350 \\
\hline $\boldsymbol{\sigma}_{\boldsymbol{p h e n}}^{2}$ & 166.0996 & 166.9973 & 0.1961 & 189.7782 & 142.5151 & 1291.1825 & 168.2624 \\
\hline $\boldsymbol{h}_{\boldsymbol{a}}^{\mathbf{2}}$ & 0.47 & 0.58 & 0.42 & 0.31 & 0.30 & 0.24 & 0.31 \\
\hline $\boldsymbol{c}_{\boldsymbol{p}}^{\mathbf{2}}$ & 0.06 & 0.03 & 0.02 & 0.10 & 0.02 & 0.05 & 0.11 \\
\hline $\boldsymbol{C} \boldsymbol{V}_{\boldsymbol{g} \boldsymbol{i}}(\%)$ & 13.50 & 21.18 & 8.93 & 18.86 & 30.77 & 53.82 & 24.48 \\
\hline $\boldsymbol{C} \boldsymbol{V}_{\boldsymbol{e}}(\%)$ & 13.60 & 17.42 & 10.34 & 26.08 & 46.12 & 93.47 & 33.63 \\
\hline $\boldsymbol{C} \boldsymbol{V}_{\boldsymbol{r}}(\%)$ & 0.99 & 1.22 & 0.86 & 0.72 & 0.67 & 0.58 & 0.73 \\
\hline $\boldsymbol{\mu}$ & 65.29 & 46.38 & 3.21 & 40.61 & 21.33 & 32.51 & 29.36 \\
\hline
\end{tabular}

$\sigma_{a}^{2}$ : additive genetic variance, $\sigma_{p}^{2}$ : genetic variance between populations, $\sigma_{e}^{2}$ : residual variance, $\sigma_{p h e n}^{2}:$ individual phenotypic variance, $h_{a}^{2}$ : individual narrow-sense heritability, $c_{p}^{2}$ : coefficient of determination of genetic effects of populations, $C V_{g i}$ : coefficient of individual additive genetic variation, $C V_{e}$ : coefficient of residual variation, $C V_{r}$ : coefficient of relative variation, and $\mu$ : overall mean.

The residual coefficients of variation were high and higher than the estimates of the respective genetic coefficients of variation for the FN and RBN traits. Consequently, these traits exhibited the lowest relative coefficients of variation $(0.58$ and 0.67 , respectively). The highest relative coefficient of variation was obtained by TD130 (1.22), indicating that considerable gains can be obtained through selection for that trait.

Individual narrow-sense heritabilities ranged from $0.24(\mathrm{FN})$ to 0.58 (TD130). According to Resende (2002), these traits had been heritabilities of moderate $\left(0.15<h_{a}^{2}<0.50\right)$ to high $\left(h_{a}^{2}>\right.$ $0.50)$ magnitude. It should be noted that individual narrow-sense heritability for TD130 was higher than for TD10. Narrow-sense heritability measures the proportion of phenotypic variance due to additive genetic effects (Resende, 2015). Thus, TD130 showed to be a more effective variable to quantify the additive genetic variance.

Fruit number showed high phenotypic variance, averaging 32.51 units per plant (Table 1). Some plants did not bear fruit, which was expected, considering it was the first harvest. Many authors have reported the possibility of evaluating the quality of peach fruit three years after seedling emergence, when planting is performed directly in the field (Hanshe, 1990; Souza et al., 1998, 2000; Wagner Júnior et al., 2011). The use of genotypes with a shorter juvenile phase is advantageous for breeding programs in that it maximizes gain with selection per unit of time, increasing the efficiency of the program (Bruckner and Wagner Júnior, 2008).

The harvest period was from November 1st to December 28. According to Barbosa et al. (1990), these genotypes may be classified as medium- to late-maturing. In regions with mild climatic conditions, it is advantageous to select adapted, early-flowering genotypes with a short fruit development period, as they provide earlier maturation and harvest.

The average RBN was 21.33. Lack of bud formation occurs mainly in genotypes cultivated in tropical and subtropical climates (Boonprakob and Byrne, 1990; Wert et al., 2007). Richards et al. (1994) evaluated peach genotypes with low chill requirements in Florida (USA) and observed high variability for this trait. The authors concluded that the high temperatures occurring at the time of intense growth and flower differentiation contributed to the increase in RBN. 
The estimates of variance components and genetic and non-genetic parameters for the fruit traits are presented in Table 2. Considering the genetic coefficients of variation, genetic variability was observed for all traits. The highest genetic coefficients of variation were obtained for PRE (123.24), TSS/TTA (33.74) and TTA (25.93); and the lowest for FD/FL (2.98), FD (5.21) and FL (5.61).

The average PRE was 6.10. This low value was due to the existence of a high number of genotypes whose fruits have an epidermis with lack of red pigmentation. FD averaged was $44.93 \mathrm{~mm}$. Fruits with a diameter between 35 and $45 \mathrm{~mm}$ are classified as small - category 2 (PBMH and PIF, 2008). Medium to large fruits (diameter greater than $50 \mathrm{~mm}$ ) are preferred by the consumer (Trevisan et al., 2010). Thus, selection should prioritize the FD trait to meet the consumer's preference.
Except for PRE, the residual fractions of the phenotypic variances were higher than the genetic fractions $\left(C V_{r}<1\right)$. Moreover, the experimental coefficients of variation were high. However, Resende and Duarte (2007) reported the possibility of obtaining high selection accuracies, even with high experimental coefficients of variation, as long as the genotypic coefficient of variation and the number of repetitions is high, which was the present case.

Individual narrow-sense heritability estimates ranged from 0.08 (AP) to 0.43 (PRE). According to Resende (2002), these traits had been heritabilities of low $\left(h_{a}^{2}<0.15\right)$ to moderate $\left(0.15<h_{a}^{2}<\right.$ $0.50)$ magnitude. In traits with lower heritabilities, a higher proportion of phenotypic variance is explained by non-genetic effects, which is a complicating factor in selection.

Table 2. Estimates of variance components and genetic and non-genetic parameters for the following traits evaluated in $\mathrm{S}_{2}$ peach populations at two years old: fruit weight $(\mathrm{FW})$, fruit diameter (FD), fruit length (FL), fruit diameter/length ratio (FD/FL), percentage of red in the epidermis (PRE), apex prominence (AP), suture line prominence (SLP), total soluble solids content (TSS), total titratable acidity (TTA) and soluble solids content/titratable acidity ratio (TSS/TTA).

\begin{tabular}{ccccccccccc}
\hline Estimate / Parameter & FW & FD & FL & FD/FL & PRE & AP & SLP & TSS & TTA & TSS/TTA \\
\hline $\boldsymbol{\sigma}_{\boldsymbol{a}}^{2}$ & 60.5790 & 5.4803 & 7.5000 & 0.0011 & 56.5908 & 0.0620 & 0.0271 & 0.5807 & 0.0169 & 82.8731 \\
\hline $\boldsymbol{\sigma}_{\boldsymbol{p}}^{2}$ & 0.1879 & 0.0067 & 2.6872 & 0.0010 & 7.8199 & 0.1036 & 0.0281 & 0.0021 & 0.0002 & 0.4915 \\
$\boldsymbol{\sigma}_{\boldsymbol{r}}^{2}$ & - & 5.6539 & 8.8020 & 0.0014 & 35.3155 & 0.0910 & 0.0763 & - & - & - \\
$\boldsymbol{\sigma}_{\boldsymbol{i}}^{\mathbf{2}}$ & - & 0.1460 & 0.1978 & 0.0000 & 0.3452 & 0.0013 & 0.0035 & - & - & - \\
\hline $\boldsymbol{\sigma}_{\boldsymbol{e}}^{\mathbf{2}}$ & 92.0964 & 10.1052 & 13.7886 & 0.0038 & 30.9101 & 0.2352 & 0.2204 & 1.8349 & 0.0330 & 150.1558 \\
\hline $\boldsymbol{\sigma}_{\boldsymbol{p h e n}}^{2}$ & 152.8634 & 21.3907 & 32.9739 & 0.0073 & 130.9680 & 0.4932 & 0.3555 & 2.4178 & 0.0502 & 233.5204 \\
\hline $\boldsymbol{h}_{\boldsymbol{a}}^{2}$ & 0.40 & 0.26 & 0.23 & 0.15 & 0.43 & 0.13 & 0.08 & 0.24 & 0.34 & 0.35 \\
\hline $\boldsymbol{c}_{\boldsymbol{p}}^{\mathbf{2}}$ & 0.0001 & 0.000 & 0.081 & 0.133 & 0.060 & 0.210 & 0.079 & 0.001 & 0.004 & 0.002 \\
\hline $\boldsymbol{c}_{\boldsymbol{r}}^{2}$ & - & 0.26 & 0.27 & 0.19 & 0.27 & 0.18 & 0.21 & - & - & - \\
\hline $\boldsymbol{c}_{\boldsymbol{i}}^{2}$ & - & 0.01 & 0.01 & 0.01 & 0.00 & 0.00 & 0.01 & - & - & - \\
\hline $\boldsymbol{\rho}$ & - & 0.52 & 0.58 & 0.47 & 0.76 & 0.52 & 0.37 & - & - & - \\
\hline $\boldsymbol{r}_{\boldsymbol{g} \boldsymbol{m}}$ & - & 0.97 & 0.97 & 0.96 & 0.99 & 0.98 & 0.88 & - & - & - \\
\hline $\boldsymbol{C} \boldsymbol{V}_{\boldsymbol{g} \boldsymbol{i}}$ & 14.71 & 5.21 & 5.61 & 2.98 & 123.24 & 14.94 & 8.12 & 7.17 & 25.93 & 33.74 \\
\hline $\boldsymbol{C} \boldsymbol{V}_{\boldsymbol{e}}$ & 18.14 & 7.08 & 7.61 & 5.67 & 91.08 & 29.11 & 23.17 & 12.74 & 36.21 & 45.42 \\
\hline $\boldsymbol{C} \boldsymbol{V}_{\boldsymbol{r}}$ & 0.81 & 0.74 & 0.74 & 0.53 & 1.35 & 0.51 & 0.35 & 0.56 & 0.72 & 0.74 \\
\hline $\boldsymbol{\mu}$ & 52.91 & 44.93 & 48.82 & 1.09 & 6.10 & 1.67 & 2.03 & 10.63 & 0.50 & 26.98 \\
\hline
\end{tabular}

$\sigma_{a}^{2}$ : additive genetic variance, $\sigma_{p}^{2}$ : genetic variance between populations, $\sigma_{r}^{2}$ : permanent environmental variance; $\sigma_{i}^{2}:$ genotype $\times$ measure interaction variance; $\sigma_{e}^{2}$ : residual variance, $\sigma_{p h e n}^{2}$ : individual phenotypic variance, $h_{a}^{2}$ : individual narrow-sense heritability, $c_{p}^{2}$ : coefficient of determination of genetic effects of populations, $c_{r}^{2}$ : coefficient of determination of permanent environmental effects, $c_{i}^{2}$ : coefficient of determination of genotype $\times$ measure interaction effects, $\rho$ : coefficient of individual repeatability, $r_{g m}$ : genetic correlation through measures, $C V_{g i}$ : coefficient of individual additive genetic variation, $C V_{e}$ : coefficient of residual variation, $C V_{r}$ : coefficient of relative variation, and $\mu$ : overall mean. 
The average SLP was 2.03, where as AP averaged was 1.67. Selection for genotypes with low values for both traits, especially AP, is desirable. The apex is the first part of the fruit to ripen and is the area most prone to mechanical damage. The fraction of phenotypic variance due to population effects was highest for the AP and FD/FL traits, whose coefficients of determination were 0.21 and 0.13 , respectively.

Repeatability coefficients in the six fruits evaluated per plant ranged from 0.37 (SLP) to 0.76 (PRE) (Table 3). According to Resende (2002), these traits has repeatability coefficients of moderate $(0.30<\rho<0.60)$ to high $(\rho>0.60)$ magnitude. The higher the repeatability value, the higher the proportion of total variance explained by the genotypes and by permanent alterations attributed to the common environment. Except for SLP, the evaluation of six fruits per plant revealed coefficients of determination greater than $80 \%$, which shows that the number of evaluated fruits was adequate to predict the genetic values (Table $3)$.

To obtain the same coefficient of determination for the SLP trait, seven fruits would have to be evaluated per plant. Increased precision can be achieved by increasing the number of evaluated fruits. Sixteen fruits must be evaluated per plant to achieve a determination coefficient higher than $90 \%$ for all traits.

Table 3. Repeatability coefficient $(\rho)$, coefficient of determination $\left(R^{2}\right)$ and fruit number $(\eta)$ to obtain different $R^{2}$ for the following traits evaluated in $\mathrm{S}_{2}$ peach populations at two years old: fruit diameter (FD), fruit length (FL), fruit diameter/length ratio (FD/FL), percentage of red in the epidermis (PRE), apex prominence (AP) and suture line prominence (SLP).

\begin{tabular}{|c|c|c|c|c|c|}
\hline \multirow{2}{*}{ Trait } & \multirow{2}{*}{$\rho^{a}$} & \multirow{2}{*}{$\mathbf{R}^{2 \mathrm{a}}$} & \multicolumn{3}{|c|}{$\eta$} \\
\hline & & & $R^{2}=0.80$ & $R^{2}=0.90$ & $R^{2}=0.95$ \\
\hline FD & 0.5208 & 0.87 & 3.68 & 8.28 & 17.48 \\
\hline $\mathrm{FL}$ & 0.5758 & 0.89 & 2.95 & 6.63 & 14.00 \\
\hline FD/FL & 0.4705 & 0.84 & 4.50 & 10.13 & 21.38 \\
\hline PRE & 0.7614 & 0.95 & 1.25 & 2.82 & 5.96 \\
\hline $\mathrm{AP}$ & 0.5203 & 0.87 & 3.69 & 8.30 & 17.52 \\
\hline SLP & 0.3700 & 0.78 & 6.81 & 15.32 & 32.35 \\
\hline
\end{tabular}

a. considering $n=6$.

Albuquerque et al. (2004) estimated a minimum of five fruits to be evaluated per plant to obtain a determination coefficient higher than $90 \%$ for FL, six for FD and nine for FD/FL. In the present study, to achieve the same precision, an estimated eight, six and 10 fruits would be necessary, respectively. Although the repeatability coefficient depends on variances of genetic and non-genetic cause, the estimates in both studies were similar.

When the main goal of a breeding program is to develop cultivars adapted to regions with mild climatic conditions, selection should prioritize genotypes with low chill requirements, especially those of early flowering and harvest and whose fruit quality is compatible with the consumers' demands.
The main characteristics in this respect would be medium to large fruit size (larger than $50 \mathrm{~mm}$ ), sweet to bittersweet flavor and reddish epidermis (Trevisan et al., 2010). Additionally, those genotypes can be recombined to form new segregating populations.

\section{Acknowledgements}

We appreciate the financial support from the Brazilian Government through the National Council for Scientific and Technological Development $(\mathrm{CNPq})$ and the Coordination for the Improvement of Higher Education Personnel (CAPES). This study was financed in part by the CAPES - Finance Code 001 .

\section{References}

ALBUQUERQUE, A.S.; BRUCKNER, C.H.; CRUZ, C.D.; SALOMÃO, L.C.C.; NEVES, J.C.L. 2004. Repeatability and correlation among peach physical traits. Crop Breeding and Applied Biotechnology, 4:441-445. http://www.sbmp.org.br/cbab/siscbab/uploads/c8128f42-4128349c.pdf 
AOAC. 1990. Association of Official Analytical Chemists: Official methods of analysis. Available from URL. https://law.resource.org/pub/us/cfr/ibr/002/aoac.methods.1.1990.pdf

BARBOSA, W.; OJIMA, M.; DALL'ORTO, F.A.C.; MARTINS, F.P. 1990. Época de ciclo de maturação de pêssegos e nectarinas no estado de São Paulo. Bragantia, 48:221-226. http://dx.doi.org/10.1590/S0006-87051990000200003

BOONPRAKOB, U.; BYRNE, D.H. 1990. Blind nodes in peach: environmental and genetic parameters. HortSciense, 25:1068. https://doi.org/10.21273/HORTSCI.25.9.1068c

BRUCKNER, C.H.; WAGNER JÚNIOR, A. 2008. Métodos de melhoramento de fruteiras. In: Bruckner, C.H. (Ed.). Fundamentos do melhoramento de fruteiras. Editora UFV, Viçosa. p. 69-116.

BRUNA, E.D.; MORETO, A.L.; DALBO, M.A. 2012. Uso do coeficiente de repetibilidade na seleção de clones de pessegueiro para o litoral sul de Santa Catarina. Revista Brasileira de Fruticultura, 34:206-215. http://dx.doi.org/10.1590/S0100-29452012000100028

CANTILLANO, R.F.F.; SACHS, S. 1984. Colheita, classificação, embalagem e armazenagem. In: EMBRAPA. A cultura do pessegueiro. Centro Nacional de Pesquisa em Fruteiras de Clima Temperado, Pelotas. p.113-119

CORRÊA, E.R.; NARDINO, M.; BARROS, W.S.; RASEIRA, M.C.B. 2019. Genetic progress of the peach breeding program of Embrapa over 16 years. Crop Breeding and Applied Biotechnology, 19(3):319-328. https://dx.doi.org/10.1590/1984-70332019v19n3a44

HANSHE, P.E. 1990. Heritability of spring Bloom and fall leaf abscision dates in Prunus persica. HortScience, 25:1639-1641. https://doi.org/10.21273/HORTSCI.25.12.1639

MATIAS, R.G.P.; BRUCKNER, C.H.; SILVA, D.F.P.; CARNEIRO, P.C.S.; SILVA, J.O.C. 2015. Repetibilidade de caracteres de fruto em pessegueiro. Revista Brasileira de Fruticultura, 37:10011008. http://dx.doi.org/10.1590/0100-2945-255/14

MONET, R.; GUYE, A.; ROY, M. 1996. Effect of inbreeding and crossing inbreed lines on the weight of peach fruit. Acta Horticulturae, 374:77-82. https://doi.org/10.17660/ActaHortic.1996.374.9

PBMH \& PIF. 2008. Normas de classificação de pêssego e nectarina. CEAGESP, São Paulo. http://www.hortibrasil.org.br.

RASEIRA, M.C.B.; NAKASU, B.H. 2002. Pessegueiro. In: Bruckner, C.H. (Ed.). Melhoramento de Fruteiras de Clima Temperado. Editora UFV, Viçosa. p. 89-126.

RESENDE, M.D.V. 2002. Genética biométrica e estatística no melhoramento de plantas perenes. Emprapa Informação Tecnológica, Brasília. 975p.

RESENDE, M.D.V. 2007. Matemática e estatística na análise de experimentos e no melhoramento genético. Embrapa Florestas, Colombo. 362p.

RESENDE, M.D.V. 2015. Genética quantitativa e de populações. Suprema, Visconde do Rio Branco. $463 \mathrm{p}$.

RESENDE, M.D.V. 2016. Software Selegen-REML/BLUP: a useful tool for plant breeding. Crop Breeding and Applied Biotechnology, 16:330-339. http://dx.doi.org/10.1590/198470332016v16n4a49. 
RESENDE, M.D.V.; DUARTE, J.B. 2007. Precisão e controle de qualidade em experimentos de avaliação de cultivares. Pesquisa Agropecuária Tropical, 37:182-194. https://www.revistas.ufg.br/pat/article/view/1867/1773

RESENDE, M.D.V.; SILVA, F.F.; AZEVEDO, C.F. 2014. Estatística matemática, biométrica e computacional: modelos mistos, categóricos e generalizados (REML/BLUP), inferência Bayesiana, regressão aleatória, seleção genômica, QTL-GWAS, estatística espacial e temporal, competição, sobrevivência. Suprema, Visconde do Rio Branco. 881p.

RICHARDS, G.D.; PORTER, G.W.; RODRIGUEZ, J.; SHERMAN, W.B. 1994. Incidence of blind nodes in low-chill peach and nectarine germplasm. Fruit Varieties Journal, 48:199-202. https://www.pubhort.org/aps/48/v48_n4_a2.htm

SOUZA, V.A.B.; BYRNE, D.H.; TAYLOR, J.F. 1998. Heritability, genetic and phenotypic correlations, and predicted selection response of quantitative traits in peach: II. An analysis of several fruit traits. Journal of American Society for Horticultural Science, 123:604-611. https://doi.org/10.21273/JASHS.123.4.604

SOUZA, V.A.B.; BYRNE, D.H.; TAYLOR, J.F. 2000. Predicted breeding values for nine plant and fruit characteristics of 28 peach genotypes. Journal of American Society for Horticultural Science, 125:460-465. https://doi.org/10.21273/JASHS.125.4.460

THUROW, L.B.; GASIC, K.; RASEIRA, M.C.B.; BONOW, S.; CASTRO, C.M. 2020. Genome-wide SNP discovery through genotyping by sequencing, population structure, and linkage disequilibrium in Brazilian peach breeding germplasm. Tree Genetics \& Genomes, 16:10. https://doi.org/10.1007/s11295-019-1406-x

THUROW, L.B.; RASEIRA, M.C.B.; BONOW, S.; ARGE, L.W.P.; CASTRO, C.M. 2017. Estrutura genética do germoplasma de melhoramento de pessegueiro no Brasil. Revista Brasileira de Fruticultura, 39(5):e-166. http://dx.doi.org/10.1590/0100-29452017166

TOPP, B.L.; SHERMAN, W.B. 2000. Breeding strategies for developing temperate fruits for the subtropics, with particular reference to Prunus. Acta Horticulturae, 522:235-240. https://doi.org/10.17660/ActaHortic.2000.522.26

TREVISAN, R.; PIANA, C.F.B.; TREPTOW, R.O.; GONÇALVES, E.D.; ANTUNES, L.E.C. 2010. Perfil e preferências do consumidor de pêssego (Prunus persica) em diferentes regiões produtoras no Rio Grande do Sul. Revista brasileira de fruticultura, 32:90-100. http://dx.doi.org/10.1590/S0100-29452010005000011

VIANA, A.P.; RESENDE, M.D.V. 2014. Genética quantitativa no melhoramento de fruteiras. Editora Interciência, Rio de Janeiro. 296p.

WAGNER JÚNIOR, A.; BRUCKNER, C.H.; CANTÍN, C.M.; SÁNCHEZ, M.A.M.; CRUZ, C.D. 2011. Divergência genética entre progênies de pessegueiro em Zaragoza, Espanha. Revista Brasileira de Fruticultura, 33:303-310. http://dx.doi.org/10.1590/S0100-29452011005000045

WERT, T.W.; WILLIAMSON, J.G.; CHAPARRO, J.X.; MILLER, P. 2007. Node type development of four low-chill peach cultivars at three locations in Florida. HortSciense, 42:1592-1595. https://doi.org/10.21273/HORTSCI.42.7.1592 